\title{
Survey of CF mutations in the clinical laboratory
}

\author{
Klaus Roland Huber*1, Borka Mirkovic ${ }^{1}$, Rhea Nersesian², Angela Myers², \\ Randall Saiki ${ }^{2}$ and Kurt Bauer ${ }^{1}$
}

Address: ${ }^{1}$ Ludwig Boltzmann Institute for moleculargenetic laboratory diagnostics, Donauspital, Vienna, Austria and ${ }^{2}$ Roche Molecular Systems, Inc., Alameda, CA, USA

E-mail: Klaus Huber* - klaus.huber@smz.magwien.gv.at; Borka Mirkovic - Borka.Mirkovic@smz.magwien.gv.at;

Rhea Nersesian - rhea.nersesian@roche.com; Angela Myers - angela.myers@roche.com; Randall Saiki - Randall_Saiki@roche.com;

Kurt Bauer - Kurt.Bauer@smz.magwien.gv.at

${ }^{*}$ Corresponding author

Published: 19 November 2002

Received: 2 September 2002

BMC Clinical Pathology 2002, 2:4

Accepted: 19 November 2002

This article is available from: http://www.biomedcentral.com/1472-6890/2/4

(c) 2002 Huber et al; licensee BioMed Central Ltd. This is an Open Access article: verbatim copying and redistribution of this article are permitted in all media for any purpose, provided this notice is preserved along with the article's original URL.

\begin{abstract}
Background: Since it is impossible to sequence the complete CFTR gene routinely, clinical laboratories must rely on test systems that screen for a panel of the most frequent mutations causing disease in a high percentage of patients. Thus, in a cohort of 257 persons that were referred to our laboratory for analysis of CF gene mutations, reverse line probe assays for the most common CF mutations were performed. These techniques were evaluated as routine first-line analyses of the CFTR gene status.
\end{abstract}

Methods: DNA from whole blood specimens was extracted and subjected to PCR amplification of 9 exons and 6 introns of the CFTR gene. The resulting amplicons were hybridised to probes for $\mathrm{CF}$ mutations and polymorphisms, immobilised on membranes supplied by Roche Molecular Systems, Inc. and Innogenetics, Inc.. Denaturing gradient gel electrophoresis and sequencing of suspicious fragments indicating mutations were done with CF exon and intron specific primers.

Results: Of the 257 persons tested over the last three years (referrals based on I) clinical symptoms typical for/indicative of CF, 2) indication for in vitro fertilisation, and 3) gene status determination because of anticipated parenthood and partners or relatives affected by $\mathrm{CF}$ ), the reverse line blots detected heterozygote or homozygote mutations in the CFTR gene in 68 persons (26\%). Eighty-three percent of those affected were heterozygous (47 persons) or homozygous ( 10 persons) for the $\triangle \mathrm{F} 508$ allele. The only other $\mathrm{CF}$-alleles that we found with these tests were the G542X allele (3 persons), the G55ID allele ( 3 persons), the $3849+10 \mathrm{~kb} C-T$ allele ( 2 persons) the RII $7 \mathrm{H}$ allele ( 2 persons) and the $62 \mathrm{I}+\mathrm{IG}-\mathrm{T}$ allele (I person).

Of the fifteen IVS8-5T-polymorphisms detected in intron 8 , seven $(47 \%)$ were found in males referred to us from IVF clinics. These seven $5 \mathrm{~T}$-alleles were all coupled with a heterozygous $\Delta \mathrm{F} 508$ allele, they make up $35 \%$ of the males with fertility problems ( 20 men) referred to us.

Conclusions: In summary, the frequency of CF chromosomes in the cohort examined with these tests was $26 \%$, with the $\Delta F 508$ allele affecting $83 \%$ of the CF chromosomes. It is a substantial improvement for routine CF diagnostics to have available a test system for 30 mutations plus the polypyrimidine length variants in intron 8 . Our results show that this test system allows a routine first-line analyses of the CFTR gene status. 
Table I: Exons and introns that are amplified with the line probe assay, and the mutations they encompass

\begin{tabular}{|c|c|}
\hline \multicolumn{2}{|l|}{ Roche assay: } \\
\hline Amplicon & Mutations \\
\hline exon 4 & $\mathrm{R} I|7 \mathrm{H}, 62|+\mid \mathrm{G} \rightarrow \mathrm{T}$ \\
\hline exon 7 & R334W, R347P \\
\hline exon 9 & A455E, 5/7/9T polymorphism \\
\hline exon 10 & $\Delta \mathrm{I} 507, \Delta \mathrm{F} 508 . \mathrm{F} 508 \mathrm{C}, 1507 \mathrm{~V}, 1506 \mathrm{~V}$ polymorphism \\
\hline exon II & I7I7-IG $\rightarrow$ A, G542X, S549N, G55ID, R553X, R560T \\
\hline exon 20 & WI282X \\
\hline exon 21 & NI303K \\
\hline intron 19 & $3849+10 \mathrm{~kb} \mathrm{C} \rightarrow \mathrm{T}$ \\
\hline \multicolumn{2}{|c|}{ Innogenetics assay: } \\
\hline exon 3 & 394delTT, G85E, E60X \\
\hline exon/intron 4 & $62 I+I G-T, R I I 7 H$ \\
\hline exon 7 & I078delT, R347P, R334W \\
\hline exon 13 & 2143 delT, $2183 \mathrm{AA}-\mathrm{G}, 2184 \mathrm{del} A$ \\
\hline exon 19 & RII62X, 3659delC \\
\hline intron 5 & $7 I I+5 G-A$ \\
\hline intron8/exon 9 & A455E,, 5T,7T,9T \\
\hline intron $14 \mathrm{~b}$ & $2789+5 G-A$ \\
\hline intron 19 & $3849+10 \mathrm{~kb} \mathrm{C}-\mathrm{T}$ \\
\hline
\end{tabular}

\section{Background}

Diagnosis of hereditary human disease to date requires arduous techniques and intense manual handling. When a disorder is caused by mutations in a large gene and at multiple loci, the demands pose considerable challenges to the testing laboratory. In some cases, the underlying mutations can not be found at all, because it is impossible to sequence complete genes routinely. Consequently, clinical laboratories must rely on test systems that screen for a panel of the most frequent mutations causing disease in a high percentage of patients, in order to minimise the need for further elaborate protocols.

Accordingly, for the diagnosis of mutations that lead to cystic fibrosis, a panel of methods is needed, i.e. PCRbased techniques, reverse blots, DGGE, sequencing a.s.o [1]. The demand for improved tools for CF diagnostics is substantial, because cystic fibrosis is among the most common autosomal recessive diseases in the Caucasian population. It affects 1:2000-1:3000 births each year and results in pulmonary failure and death in most cases at around the third decade of life [2]. The molecular defect in CF was elucidated following the cloning of the cystic fibrosis transmembrane conductance regulator (CFTR) gene [3]. So far, over 800 different mutations are recorded that lie in introns and exons. Recently, association of CFTR mutations with other diseases - such as congenital bilateral absence of vasa deferentia (CBAVD) $[4,5]$ disseminated bronchiectasis [6], or allergic bronchopulmonary aspergillosis [7] - have emerged. This is not surprising considering the cellular heterogeneity of CFTR expression and the multiple mutations in this gene [8-
10]. In the case of CBAVD a strong association between the repeat number of a polypyrimidine tract in intron 8 of the CF gene with the absence of the vas deferens was found $[11,12]$.

Our laboratory performs CF diagnostics for the northeastern part of Austria. In this area - including and surrounding Vienna - reside approximately three million individuals. We have been using reverse line blot assays for CF mutations that encompass up to 29 mutations, 3 polymorphisms, and 3 alleles of the intron 8 polypyrimidine tract for a rapid first screening of patient samples (table 1) complemented by DGGE and sequencing as indicated (table 2). The test panel fared well in the ECCACF (European Community Concerted Action for Cystic Fibrosis) Quality Control Trial of 1997, 1998, 1999, 2000, and 2001.

The aim of this study was the exploration of the screening procedure for CF mutations employed in our laboratory as a first-line diagnostic instrument for Cystic Fibrosis. Here, we report our experiences with various test systems and the resultant CF mutations in persons from northeastern Austria, referred to our laboratory for CF diagnosis since 1999.

\section{Methods Patients}

In all, 135 men and 122 women were analysed. The male group consisted of 64 children $(<1-18$ yrs) and 71 adults (mean age of 32 yrs, range 19-69). The group of females included 56 children ( $<1-18$ yrs) and 66 adults (mean age of 31 yrs, range 19-65). All probands (or their par- 
Table 2: Genotypes of patients with mutations, final results

Group I) (patients with symptoms typical for/indicative of CF)

\begin{tabular}{|c|c|c|c|c|c|c|c|c|}
\hline No.: & Diagnosis $^{a}$ & Sex & Age & Intron 8 & 16 mut. & 29 mut.b & seq.c & DGGEd \\
\hline 1 & $2 \times$ path. IRT, normal sweat test & $f$ & 0 & 7T/9T & DF508/3849+ I0kb C-T & $x$ & & \\
\hline 2 & CF, substantiation & $f$ & 0 & 9T/9T & $62|+| G-T / 62|+| G-T$ & & & \\
\hline 3 & CF, substantiation & $f$ & 1 & $9 \mathrm{~T} / 9 \mathrm{~T}$ & DF508/DF508 & $x$ & & \\
\hline 4 & CF, substantiation & $f$ & 5 & 9T/9T & DF508/DF508 & $x$ & $x$ & $x$ \\
\hline 5 & CF, substantiation & $f$ & 7 & $9 \mathrm{~T} / 9 \mathrm{~T}$ & DF508/G542X & $x$ & & $x$ \\
\hline 6 & $\begin{array}{l}\text { CF, substantiation, rec. diarrhoe, pancreas } \\
\text { insufficiency, pos. sweat test }\end{array}$ & $f$ & 8 & 9T/9T & DF508/DF508 & $x$ & & \\
\hline 7 & CF, substantiation & $f$ & 12 & 9T/9T & DF508/DF508 & $x$ & & \\
\hline 8 & CF, substantiation & $f$ & 13 & 9T/9T & DF508/DF508 & $x$ & & \\
\hline 9 & & $f$ & 13 & 7T/9T & DF508/WT & & & \\
\hline 10 & CF, substantiation & $f$ & 16 & $9 \mathrm{~T} / 9 \mathrm{~T}$ & DF508/G542X & & & \\
\hline 11 & indicative linkage analysis & $f$ & 22 & $7 \mathrm{~T} / 9 \mathrm{~T}$ & DF508/WT & $x$ & & \\
\hline 12 & & $f$ & 24 & $7 \mathrm{~T} / 9 \mathrm{~T}$ & DF508/WT & $x$ & & \\
\hline 13 & $\begin{array}{l}\text { bronchiectasis, bronchopulmonal infections } \\
\text { since infancy }\end{array}$ & $f$ & 28 & $7 \mathrm{~T} / 9 \mathrm{~T}$ & DF508/3849+10kbC-T & $x$ & & \\
\hline 14 & pos. sweat test & $f$ & 28 & 9T/9T & DF508/WT & $x$ & & \\
\hline 15 & typical clinic, pos. sweat test & $f$ & 31 & 7T/9T & DF508/WT & & $x$ & $x$ \\
\hline 16 & & $f$ & 32 & 7T/7T & $3849+10 \mathrm{~kb}$ C-T/WT & & & \\
\hline 17 & pulmonal course typical of CF & $f$ & 32 & $7 \mathrm{~T} / 9 \mathrm{~T}$ & DF508/WT & $x$ & $x$ & $x$ \\
\hline 18 & & $f$ & 34 & 7T/7T & G55ID/WT & & $x$ & $x$ \\
\hline 19 & & $f$ & 41 & 7T/7T & DF508/WT & & & \\
\hline 20 & CF, substantiation & $f$ & 56 & $7 \mathrm{~T} / 9 \mathrm{~T}$ & DF508/3849+10kb C-T & $x$ & & \\
\hline 21 & & & & & & & & \\
\hline 22 & CF, substantiation & $\mathrm{m}$ & 0 & 9T/9T & DF508/DF508 & $x$ & & \\
\hline 23 & & $\mathrm{~m}$ & I & $7 \mathrm{~T} / 9 \mathrm{~T}$ & DF508/WT & $x$ & & \\
\hline 24 & impaired lung function, intestinal complications & $\mathrm{m}$ & 3 & $7 \mathrm{~T} / 9 \mathrm{~T}$ & DF508/WT & & $x$ & $x$ \\
\hline 25 & CF, substantiation & $\mathrm{m}$ & 5 & 9T/9T & DF508/DF508 & & & \\
\hline 26 & & $\mathrm{~m}$ & 12 & 7T/7T & G55ID/WT & & $x$ & $x$ \\
\hline 27 & CF, substantiation & $\mathrm{m}$ & 17 & 9T/9T & DF508/DF508 & & & \\
\hline 28 & & $\mathrm{~m}$ & 18 & 7T/7T & RII7H/WT\&I466delAATT/I466delAATT & & |466delAATT & $x$ \\
\hline 29 & pos sweat test & $\mathrm{m}$ & 20 & $7 \mathrm{~T} / 9 \mathrm{~T}$ & DF508/WT & & & \\
\hline 30 & CF, substantiation & $\mathrm{m}$ & 25 & 9T/9T & DF508/DF508 & & & \\
\hline 31 & . & $\mathrm{m}$ & 26 & $5 \mathrm{~T} / 9 \mathrm{~T}$ & DF508/WT & & & \\
\hline 32 & & $\mathrm{~m}$ & 30 & $5 \mathrm{~T} / 9 \mathrm{~T}$ & DF508/WT & & & \\
\hline 33 & CF, substantiation & $\mathrm{m}$ & 31 & $7 \mathrm{~T} / 9 \mathrm{~T}$ & DF508/I248A-G & $x$ & $1248 \mathrm{~A} / \mathrm{G}$ & $x$ \\
\hline 34 & $\begin{array}{l}2 \times \text { pos. sweat tests, bronchopul. infect., } \\
\text { azoospermia, pancreatitis }\end{array}$ & $\mathrm{m}$ & 31 & 9T/9T & DF508/WT & & & \\
\hline 35 & CF, substantiation & $\mathrm{m}$ & 33 & 9T/9T & DF508/DF508 & $x$ & & \\
\hline 36 & & $\mathrm{~m}$ & 33 & $7 \mathrm{~T} / 9 \mathrm{~T}$ & DF508/WT & & & \\
\hline 37 & & $\mathrm{~m}$ & 33 & $7 \mathrm{~T} / 9 \mathrm{~T}$ & DF508/WT & & & \\
\hline 38 & & $\mathrm{~m}$ & 38 & $7 \mathrm{~T} / 9 \mathrm{~T}$ & RII7H/G542X & & & \\
\hline
\end{tabular}

Group 2a) (Patients from IVF clinics)

\begin{tabular}{|c|c|c|c|c|c|c|c|c|}
\hline No.: & Diagnosis & Sex & Age & Intron 8 & 16 mut. & 29 mut.b & seq. ${ }^{c}$ & DGGEd \\
\hline 39 & & $\mathrm{~m}$ & 24 & $7 \mathrm{~T} / 9 \mathrm{~T}$ & WT & & & \\
\hline 40 & & $\mathrm{~m}$ & 25 & 9T/9T & WT & & & \\
\hline 41 & & $\mathrm{~m}$ & 28 & $5 \mathrm{~T} / 9 \mathrm{~T}$ & DF508/WT & $x$ & & \\
\hline 42 & & $\mathrm{~m}$ & 28 & $5 \mathrm{~T} / 9 \mathrm{~T}$ & DF508/WT & & & \\
\hline 43 & & $\mathrm{~m}$ & 29 & $5 \mathrm{~T} / 9 \mathrm{~T}$ & DF508/WT & $x$ & $x$ & $x$ \\
\hline 44 & & $\mathrm{~m}$ & 30 & 7T/7T & WT & $x$ & & \\
\hline 45 & & $\mathrm{~m}$ & 31 & $5 \mathrm{~T} / 9 \mathrm{~T}$ & DF508/WT & $x$ & $x$ & $x$ \\
\hline 46 & & $\mathrm{~m}$ & 31 & $7 T / 7 T$ & WT & $x$ & & \\
\hline 47 & & $\mathrm{~m}$ & 31 & $7 \mathrm{~T} / 9 \mathrm{~T}$ & WT & $x$ & & \\
\hline 48 & & $\mathrm{~m}$ & 33 & $7 \mathrm{~T} / 9 \mathrm{~T}$ & DF508/WT & $x$ & & \\
\hline 49 & & $\mathrm{~m}$ & 34 & 7T/7T & WT & $x$ & & \\
\hline 50 & & $\mathrm{~m}$ & 34 & $9 \mathrm{~T} / 9 \mathrm{~T}$ & DF508/WT & $x$ & & \\
\hline 51 & & $\mathrm{~m}$ & 35 & $7 \mathrm{~T} / 9 \mathrm{~T}$ & G542X/WT & & & \\
\hline 52 & & $\mathrm{~m}$ & 36 & $5 T / 9 T$ & DF508/WT & & & \\
\hline
\end{tabular}


Table 2: Genotypes of patients with mutations, final results (Continued)

\begin{tabular}{|c|c|c|c|c|c|c|c|}
\hline 53 & $\mathrm{~m}$ & 39 & $5 \mathrm{~T} / 9 \mathrm{~T}$ & DF508/WT & $x$ & & $x$ \\
\hline 54 & $\mathrm{~m}$ & 40 & 7T/7T & WT & & & \\
\hline 55 & $\mathrm{~m}$ & 40 & $5 \mathrm{~T} / 9 \mathrm{~T}$ & DF508/WT & $x$ & $x$ & $x$ \\
\hline 56 & $\mathrm{~m}$ & 44 & $9 \mathrm{~T} / 9 \mathrm{~T}$ & WT & & & \\
\hline 57 & $\mathrm{~m}$ & 45 & 7T/7T & WT & $x$ & & \\
\hline 58 & $\mathrm{~m}$ & 47 & $7 \mathrm{~T} / 7 \mathrm{~T}$ & WT & & & \\
\hline
\end{tabular}

Group 3) (Patients with relatives having CF)

\begin{tabular}{|c|c|c|c|c|c|c|c|c|}
\hline No.: & Diagnosis & Sex & Age & Intron 8 & 16 mut. & 29 mut.b & seq.c & DGGEd $^{d}$ \\
\hline 59 & & $f$ & 42 & 7T/7T & $3849+10 \mathrm{~kb}$ C-T/WT & $x$ & & \\
\hline 60 & & $f$ & 15 & 7T/9T & DF508/WT & $x$ & & \\
\hline 61 & & $f$ & 20 & 7T/9T & DF508/WT & $x$ & & \\
\hline 62 & & $f$ & 23 & 7T/9T & DF508/WT & $x$ & & \\
\hline 63 & & $f$ & 25 & 7T/9T & DF508/WT & $x$ & $x$ & $x$ \\
\hline 64 & & $f$ & 26 & 7T/9T & DF508/WT & & & \\
\hline 65 & & $f$ & 32 & 7T/9T & DF508/WT & $x$ & & \\
\hline 66 & & $f$ & 40 & 7T/9T & DF508/WT & $x$ & & $x$ \\
\hline 67 & & $f$ & 65 & 9T/9T & DF508/WT & & & \\
\hline 68 & & $f$ & 30 & 7T/9T & DF508/WT & $x$ & & \\
\hline 69 & & $\mathrm{~m}$ & 14 & $9 \mathrm{~T} / 9 \mathrm{~T}$ & DF508/WT & $x$ & & \\
\hline 70 & & $\mathrm{~m}$ & 16 & 7T/9T & DF508/WT & & & \\
\hline 71 & & $\mathrm{~m}$ & 25 & 7T/9T & DF508/WT & $x$ & $x$ & $x$ \\
\hline 72 & & $\mathrm{~m}$ & 28 & $5 \mathrm{~T} / 9 \mathrm{~T}$ & DF508/WT & $x$ & & \\
\hline 73 & & $\mathrm{~m}$ & 32 & $7 \mathrm{~T} / 9 \mathrm{~T}$ & DF508/WT & $x$ & & $x$ \\
\hline 74 & & $\mathrm{~m}$ & 45 & 7T/9T & DF508/WT & $x$ & & $x$ \\
\hline 75 & & $\mathrm{~m}$ & 48 & $7 \mathrm{~T} / 9 \mathrm{~T}$ & DF508/WT & $x$ & & \\
\hline 76 & & $\mathrm{~m}$ & 69 & 7T/9T & DF508/WT & & & \\
\hline 77 & & $\mathrm{~m}$ & 30 & 7T/9T & G542X/WT & $x$ & & $x$ \\
\hline 78 & & $\mathrm{~m}$ & 15 & 7T/7T & G55ID/WT & $x$ & & \\
\hline
\end{tabular}

Details for diagnoses, number of mutations analysed, methods used, and other specifics for individuals with found mutations within the three groups are shown. A complete documentation comprising all persons examined is available upon request. Asterisks denote samples that were tested additionally to the Roche assay. In two cases, mutations were found only by sequencing, these mutations are shown in the column "seq". Other than that, all mutations were found merely by the Roche assay. aThe diagnoses are shown for the individuals specified. In the cases, where no diagnosis are given, the referrals were based on clinical symptoms suspicious for CF. No special diagnosis is given for the group of patients from IVF clinics and probands with relatives having CF. bThe asterisk denotes individuals that were analysed for 29 mutations (see table I). cFragments (one to five) were sequenced when the DGGE analysis $d$ showed bands indicating heterozygosity.

ents, respectively) had given informed consent for genetic analysis as required by the Austrian law. Patients and probands referrals to our laboratory for CF mutation analyses were based on

1) clinical symptoms typical for/indicative of CF,

2) indication for in vitro fertilisation (IVF - group 2a: men, 2b: their spouses), and

3) gene status determination because of anticipated parenthood and partners or relatives affected by CF.

Of all 257 persons analysed for CF mutations, 105 were examined for 16 mutations, 152 for 29 mutations, 31 individuals were tested further by DGGE of all exons and sequencing of suspicious fragments.

\section{DNA studies}

DNA was extracted routinely from blood using the Kristal $^{\mathrm{TM}}$ DNA extraction kit (Cambridge Molecular Technologies, Cambridge, England). The INNO-LiPa CFTR17+Tn (INNOGENETICS, Ghent, Belgium) assay was performed according to the recommendation of the supplier.

For the evaluation of the Amplicor ${ }^{\circledR}$ Cystic Fibrosis kit (Roche Molecular Systems, Alameda, CA, USA), the extraction protocol included in the kit was tested, as well. For this test, $100 \mu \mathrm{L}$ blood was incubated 5 to $10 \mathrm{~min}$ with $1 \mathrm{ml}$ "Specimen Wash Solution" as supplied in the test kit in Eppendorf vials to lyse red blood cells. The solution was centrifuged for $1 \mathrm{~min}$ at maximum speed in a microfuge and the supernatant was discarded. The leucocyte pellet was treated once more with "Specimen Wash Solu- 
tion" as above. The final pellet was taken up in "Extraction Reagent" and the subsequent steps were performed analogous to Kristal kit-extracted DNA: Cell pellets or DNA (minimum of $400 \mathrm{ng}$ in a volume of $50 \mu \mathrm{L}$ or less) were incubated in $200 \mu \mathrm{L}$ Extraction Reagent for $30 \mathrm{~min}$ at $100^{\circ} \mathrm{C}$. Twenty-five $\mu \mathrm{L}$ of this solution were PCR-amplified with $25 \mu \mathrm{L}$ of $16.5 \mathrm{mmol} / \mathrm{L}$ Magnesium Chloride solution and $50 \mu \mathrm{L}$ PCR "Mastermix" according to the manufacturers specification. The resulting amplicons were denatured immediately with "Denaturing Solution" to inhibit the action of uracyl-N-glycosylase (Amperase) present in the Mastermix. The panels with immobilised probes for 16 CFTR mutations and some polymorphisms were prehybridised for 10 min with "Hybridisation Buffer" (3× SSPE + 0.5\% SDS). Then, $100 \mu \mathrm{L}$ denatured amplicons were hybridised to the probes for $20 \mathrm{~min}$ at $50^{\circ} \mathrm{C}$ in hybridisation buffer. After a stringent wash for $12 \mathrm{~min}$ at $50^{\circ} \mathrm{C}$ with "Wash Buffer" ( $2 \times$ SSPE $+0.3 \%$ SDS $)$ the panels were incubated with Streptavidin-Horseradish-Peroxidase-Conjugate. After further wash steps, addition of substrate (hydrogen peroxide + tetramethylbenzidine) produces a blue precipitate at the regions of hybridisation. Individual bands can be identified by superimposing a transparent foil with the identification codes imprinted.

\section{DGGE analyses and sequencing}

For the individuals specified in table 2), all exons were analysed by DGGE according to Audrezet et al. [20]. Suspicious fragments indicating mutations were sequenced on a Licor $4000 \mathrm{~L}$ sequencing machine.

\section{Results \\ Patients}

Patients and probands referrals to our laboratory for CF mutation analyses were based on

1) clinical symptoms typical for/indicative of $\mathrm{CF}$, (the clinical symptoms that prompted analysis for CF gene status comprised: prior positive tests for immune reactive trypsinogen (IRT), positive sweat test (> $60 \mathrm{mmol}$ chloride/L), lung disease (bronchiectasies), and others,

2) indication for in vitro fertilisation (IVF - group 2a: men, 2b: their spouses), and

3) gene status determination because of anticipated parenthood and partners or relatives affected by CF.

The first group (symptomatic) was comprised of 83 male (mean age: 29 yrs, range: $19-48$ yrs) and 88 female patients (mean age: 31 yrs, range: $19-61$ yrs) with 114 children/adolescents ( 60 male, 54 female) from $<1$ to $18 \mathrm{yrs}$, the mean age of this group was 13.5 yrs. The clinical symptoms for the individuals with mutations (where giv- en) are shown in table 2), a complete list is available upon request.

The group 2a) (IVF) referred to us from IVF clinics included 20 men (mean age: 34 yrs, range $24-47$ yrs), group $2 b$ (IVF) twelve of their spouses with a mean age of $30 \mathrm{yrs}$ (range: 22-36 yrs) and a presumable risk of being a CF carrier equal to the population risk. Clinical symptoms in men included CBAVD, atrophy of the testes, aplasy of the ductus deferens, aplasy of the epidymes, and azoospermia. The women in group $2 \mathrm{~b}$ (all without clinical symptoms) were referred to $\mathrm{CF}$ analysis for gene status determination in the context of in vitro fertilisation.

Group 3 (mean age: 29 yrs, range: 9-69 yrs) consisted of 26 men and 28 women. These persons wanted their gene status to be determined, because either their children or close relatives were afflicted by CF. The group included 17 couples and 12 individuals that wanted to be tested in the context of planned parenthood.

\section{Amplicor cystic fibrosis test}

The Roche Amplicor CF mutation test strip was evaluated by analysing in parallel 100 samples with a panel of techniques established in our laboratory (Inno LiPa reverse dot blot - first generation, DGGE, sequencing). For 27 persons in this cohort this included sequencing of one to five exons. Besides various polymorphisms, only one splice site and one frameshift mutation were found. Thus, $97 \%$ of all mutations in this cohort that we could find routinely following our established protocols could be analysed with the Roche Amplicor Cystic Fibrosis test.

The test is based on three major processes: Polymerase chain reaction target amplification, hybridisation of the amplified products to specific oligonucleotide probes, and detection of the probe-bound amplified product by colour formation.

DNA is extracted from minute amounts of patients blood by lysis of the red blood cells and incubation in Extraction Buffer at $100^{\circ} \mathrm{C}$. This method is quick ( $45 \mathrm{~min}$ ) and results in very good quality of DNA. Subsequently, the DNA is PCR amplified with 8 pairs of biotinylated primers that simultaneously amplify eight different regions of the CFTR gene (Table 1 - amplified regions plus the mutations they encompass). In addition to the analysis of 16 common mutations, the assay yields information about the poly- $T$ tract in intron 8 and polymorphisms at locus F508. Single base exchanges at this locus could lead to a lesser extent of hybridisation to the gene probes that distinguish between F508 and $\Delta \mathrm{F} 508$. By comparison to the hybridisation pattern at the polymorphic probes (see Fig. 1), misinterpretation can be excluded. 
After the PCR, the amplicons are alkali denatured to form single strands which then will hybridise to bound probes. After stringent washes, a horseradish peroxidase-streptavidin complex binds to the biotin-labelled amplicons captured by the membrane bound probes via the streptavidin moiety. This conjugate is reacted after further washing steps with hydrogen-peroxide and $\mathrm{TMB}$ to form a colour complex.

\section{DNA studies}

A total of 71 patients had CFTR mutations or the 5T allele or both (table 2 - final results for all methods used), 19 patients were found to have two mutations, 49 to have one mutation (not counting the 5T allele).

Among 114 children < 18 yrs in group 1), we found 9 patients to be homozygote for $\Delta \mathrm{F} 508$, two compound heterozygote for $\Delta \mathrm{F} 508 / \mathrm{G} 542 \mathrm{X}$, one compound heterozygote for $\Delta \mathrm{F} 508 / 3849+10 \mathrm{kbC}-\mathrm{T}$, five heterozygote for $\Delta \mathrm{F} 508$, one G551D/WT, one R117H/WT, one homozygote for $621+1 \mathrm{G}-\mathrm{T}$, and one girl with $5 \mathrm{~T} / 7 \mathrm{~T}$ alleles in intron 8 (total of $18 \%$ with mutations).

Twenty-two percent of the adults in group 1) had CFTR mutations, namely two $\Delta \mathrm{F} 508 / \Delta \mathrm{F} 508$, thirteen $\Delta \mathrm{F} 508 /$ WT, one compound for R117H/WT and 1466delAATT (frameshift mutation in exon 9), one R117H/G542X, one G551D/WT, one $3849+10 \mathrm{~kb} \mathrm{C}-\mathrm{T} / \mathrm{WT}$, one compound heterozygote for $\Delta \mathrm{F} 508 / 1248+1 \mathrm{~A} \rightarrow \mathrm{G}$ (splice mutation in intron 7), and two individuals with $\Delta \mathrm{F} 508 / 3849+10 \mathrm{~kb}$ $\mathrm{C}-\mathrm{T}$. Table 2) gives the details for these individuals. Specifics for persons with no identified mutation albeit clinical indications for CF are not shown because of space limitations. They comprise 133 individuals, 54 of these were analysed for 16 mutations, 79 for 29 mutations of which 13 were examined further with DGGE and sequencing of suspicious fragments (a detailed documentation is available upon request). Virtually none of these developed CF as confirmed by our referring clinicians [22].

Group 2) consisted of 12 women (all WT/WT and 7T/7T or 7T/9T) and 20 men. Nine of these men (45\%) had normal alleles (and a benign thymidine polymorphism in intron 8) at the loci analysed, seven men had a genotype of 5T/9T with $\Delta \mathrm{F} 508 / \mathrm{WT}$, one showed 7T/9T with $\Delta \mathrm{F} 508 /$ WT, one had 9T/9T with $\Delta \mathrm{F} 508 / \mathrm{WT}$, and one had 7T/9T with G542X/WT. As such, of the 20 male patients referred to us because of infertility, $45 \%$ had the $\Delta \mathrm{F} 508$ mutation and $77 \%$ of those were additionally affected in intron 8 by the $5 \mathrm{~T}$ mutation (table 2). The women in this group (all without clinical symptoms and normal genotype) supposedly have the normal population risk of being a CF carrier. Consequently, they are arranged in the separate category $2 \mathrm{~b}$.
Of 54 individuals in group 3, tested because their partners or relatives had CFTR mutations, $37 \%$ had mutated alleles: seventeen persons had the genotype $\Delta \mathrm{F} 508 / \mathrm{WT}$, one had G551D/WT, one had 3849+10kb C-T, and one person had G542X/WT (table 2).

In total, the $\Delta \mathrm{F} 508$ mutation represented $83 \%$ (57 of 68 ) of all exon mutations in this cohort (table 2). The $\Delta \mathrm{F} 508$ mutation has a strong association with the 9T allele on the same chromosome. This can be inferred because all ten $\Delta$ F508 homozygotes had 9T/9T alleles, and 37 of 38 $\Delta$ F508 heterozygotes had at least one 9T allele. On the other hand, only 25 out of $188 \mathrm{WT} / \mathrm{WT}$ genotypes had a 7T/9T, four had a 9T/9T polymorphism, but $157 \mathrm{WT} / \mathrm{WT}$ genotypes were associated with a 7T/7T polymorphism. This association of $\Delta \mathrm{F} 508$ and $9 \mathrm{~T}$ has been observed before [13]. Eight 5T alleles of a total of fifteen were found in individuals other then the men with fertility problems referred from IVF clinics.

Of all 257 persons analysed for CF mutations, 105 were examined only for 16 mutations (Roche assay), 152 for 29 mutations (Roche + Innogenetics assay), 31 individuals were tested further by DGGE of all exons and sequencing of suspicious fragments. Of the 71 CFTR mutations, 69 were found merely by the assay with 16 mutations $(\mathrm{n}=$ 257), none was found additionally with the second reverse line probe $(n=152)$, and 2 mutations were found by DGGE and sequencing $(n=31)$. Evaluation of our results by contacting the referring clinicians attested good performance of our assays: Virtually all patients with CF were found, whereas probands without mutations (by our tests) did not develop CF later on [22].

In comparison to CF mutation-frequencies in some European countries, the CF alleles we found ( $>2 \%$ ) with our tests show the following distribution in our cohort: $\Delta$ F508: 83\% (Romania:27\%, Switzerland: 43\%, Denmark: 87,2\% [19]); G542X: 4,4\% (France: 3,1\%, Italy: 4,8\%, Spain: 7,7\%); G551D: 4,4\% (UK: 3,1\%, Czechia: 4,0\%, Ireland: 6,9\%), 3849+10kbC-T: 2,9\% (Germany: 1,2\%, Poland: 2,6\%, Latvia: 12,5\%), R117H: $2,9 \%$ (Greece: 1,2\%, Ireland: 2,0\%, Norway: 3,0\%)

Because we participate in the European Quality assessment trial for Cystic Fibrosis, we could evaluate the quality of the Roche Amplicor CF test in this regard as well. In the case of the G551D/WT R553X/WT genotype, the Roche test needs careful interpretation (and ought to be improved) because the hybridisation at the one locus destabilised the hybridisation at the other locus which is only 4 bp apart. Accordingly, the line assay showed a G551D/G551D and R553X/R553X (two homozygote mutations) genotype instead of the correct G551D/WT and R553X/WT (compound heterozygote) genotype. The phe- 
notypic classification for such patient samples (full CF), however, was accurate, all other samples were typed correctly. This limitation is not unique to the Roche $\mathrm{CF}$ assay and is a characteristic of all mutation-specific assays in that sequence variations near the interrogated mutation affect test accuracy.

\section{Discussion}

Since the discovery of the cystic fibrosis transmembrane conductance regulator (CFTR) gene [14-16] the number of identified CF mutations has increased enormously. The mutations can be classified according to their influence of CFTR-mediated chloride secretion [17]. Mutations of category I, II, and III lead to complete loss of gene function (associated with pancreatic insufficiency), whereas class IV and V mutations confer altered conductance properties or reduced synthesis of the CFTR protein. Such reduced synthesis caused by varying degrees of exon 9 splicing have been found associated with three length variants within the splice acceptor site in intron 8 [18].

Numerous methods for analysing CFTR mutations are available, the number of mutations that should be tested for routine diagnostic purposes still being a question of debate. It may be best to have a two-tiered approach for mutation detection, with an economical first step and further more elaborate techniques for identifying rare mutations [19]. Because we perform the "economical first step" in our laboratory routinely, up to 29 of the most common CFTR mutations were analysed with line probe assays.

Persons to be tested for CF mutations are referred to our laboratory because of 1) symptoms typical for/indicative of $\mathrm{CF}, 2$ ) fertility problems, and 3) CF in relatives/partners. This classification was kept for ease of presentation. Because of financial and personnel restrictions, it is not possible in our laboratory to analyse all specimen by DGGE [20] and sequencing. Thus, reverse line probe assays are used as a first step analysis tool. From DNA extraction to the results the turnaround time is approximately 6 hrs. Both assays used are not automated and thus require various manual steps. But the ease with which 30 mutations and, very importantly, the thymidine polymorphism/mutation in intron 8 can be tested, make these tests adept as a diagnosis tool for CF in the clinical laboratory. Certainly, these tests were developed for the US and Europe and cannot be adapted for other ethnic groups. In summary, the frequency of CF chromosomes in the cohort examined with our tests was $26 \%$, with the $\Delta$ F508 allele affecting $83 \%$ of the CF chromosomes. This is considerably higher than the proportion of $\Delta \mathrm{F} 508$ alleles of $55 \%$ found in a previous study in southern Austria [21]. Five other mutations in CF chromosomes were found with these tests, four of which with a frequency above $2 \%$. The only other mutations detected by sequenc- ing, were a splice site mutation in intron $7(1248+1$ A-G) and a frame shift mutation in exon 9 (1466delAATT).

Austrian law requires genetic counselling for persons seeking genetic diagnosis. In this context, careful explanation of positive and negative test results must be given. Whereas the meaning of a positive test result would yield clear conclusions, a negative result does not exclude possible mutations at loci not examined by the test used. As more than 800 putative mutations in the CFTR gene are known, this has to be explained thoroughly to the patients seeking advice.

The phenotype/genotype correlation in our cohort was rather moderate: In the group of individuals referred to us because of symptoms indicative for $\mathrm{CF}$, mutations were found in only $22 \%$ of the samples. However, our test system is not inappropriate, as we have found practically all patients with $\mathrm{CF}$, whereas probands without mutations did not develop clinical signs of CF later on [22]. Thus, the increasingly pressing need for fast clinical reports was met by our tests. Even slight indications for putative disease must be analysed for their possible significance, nowadays, explaining the high number of samples with no mutations found.

Somewhat higher results (37\%) were found for individuals referred to us for genotype determination because their partners/relatives had known CF mutations. Thirty samples with a WT/WT genotype by the reverse line blot assays were analysed subsequently by DGGE and sequencing that resulted in only two further determinations of the mutant genotype. In both groups, the assays did not necessarily depict unknown mutations, but the panel of the commonest CF mutations was determined with certainty.

Very informative, though, were the results for the patients referred from in vitro fertility clinics. For more than half of the afflicted males, a conclusive analysis could be offered by the tests, and the exclusion of the most common mutations in their female partners was of utmost importance for their family planning. In this context, the determination of the 5T mutation in intron 8 was very significant. With the wealth of information now available, the association of the 5T mutation with fertility problems is evident. The $5 \mathrm{~T}$ polymorphism is considered now to be a mutation with incomplete penetrance [12]. The diminished amount of CFTR gene product generated by the splicing defect in intron 8 no longer sustains the physiological functions required.

\section{Conclusions}

Our results show that current techniques allow a routine first-line analyses of the CFTR gene status. It is a substantial improvement for routine diagnostics to have available 
a test system for 30 mutations plus the polypyrimidine length variants in intron 8. Certainly. further developments will advance the diagnostic possibilities for CF considerably. In this regard, it will be interesting to review our samples with the new generation line probe assays that are being developed, allowing a survey of up to 60 mutations [23].

\section{Competing interests}

None declared

\section{Authors' contributions}

H.K.R. conceived and coordinated the work, performed DGGE and sequencing, and prepared the manuscript. M.B. carried out the PCR and hybridisations, N.R., M.A., and S.R developed a reverse line probe assay and were helpful in preparing the manuscript, B.K. participated in the design and coordination of the study and was helpful in preparing the manuscript.

\section{Acknowledgements}

We thank Roche Molecular Systems, Inc. for providing us with reagents for this study. Our special thank goes to our referring clinicians (Prof. M. Götz, Wilhelminenspital; Prof. I. Eichler, AKH; Prof. A. Lischka, KH Glanzing; Prof. G. Lunglmayer, KH Mistelbach; Prof. H. Pflüger, KH Lainz; Prof. M. Sacher, SMZ; Prof. W. Stögmann, Preyersches KH; Prof. H. Zwick, Lainz; and many others) who have enabled us to perform this study.

\section{References}

I. Amos JA: Prenatal Diagnosis of Cystic Fibrosis. In: Genetic Disorders and the fetus (Edited by: Milunsky A) Baltimore, John Hopkins Univ. Press 1992, 4II-425

2. Welsh MJ, Tsui L-C, Bost TF, Beaudet AL: Cystic Fibrosis. In. The Metabolic and Molecular Bases of Inherited Disease (Edited by: Scriver CR, Beaudet AL, Sly WS and Valle D) New York, McGraw Hill, Inc 1995, 37993876

3. Drumm ML, Collins FS: Molecular Biology of Cystic Fibrosis. In: Molecular Medicine (Edited by: Friedmann T) New York, Academic press 1991, 33-68

4. Dumur V, Gervais R, Rigot JM, Lafitte J], Manouvrier S, Biserte J, Mazeman $E$, Roussel P: Abnormal distribution of CF $\triangle F 508$ allele in azoospermic men with congenital aplasia of epididymis and vas deferens. Lancet 1990, 336:5I2

5. Gervais R, Dumur V, Rigot JM, Lafitte JJ, Roussel P, Claustres M, Demaille J: High frequency of the RII 7H cystic fibrosismutation in patients with congenital absence of the vas deferens. N Eng J Med 1993, 328:446-447

6. Pignatti PF, Bombieri C, Benetazzo M, Casartelli A, Trabetti E, Gile LS, Martinati LC, Boner AL, Luisetti M: CFTR gene variant IVS8-5T in disseminated bronchiectasis. Am J Hum Genet 1996, 58:889892

7. Miller PW, Hamosh A, Macek M, Greenberger PA, MacLean J, Walden SM, Slavin RG, Cutting GR: Cystic fibrosis transmembrane conductance regulator (CFTR) gene mutations in allergic bronchopulmonary aspergillosis. Am J Hum Genet 1996, 59:45-5 I

8. Jiang Q, Engelhardt JF: Cellular heterogeneity of CFTR expression and function in the lung. implications for gene therapy of cystic fibrosis. Eur J Hum Genet 1998, 6: |2-31

9. Vankeerberghen A, Wie L, Jaspers M, Cassiman J-J, Nilius B, Cuppens $\mathrm{H}$ : Characterization of 19 disease-associated missense mutations in the regulatory domain of the cystic fibrosis transmembrane conductance regulator. Hum Mol Genet 1998, $7: 1761-1769$

10. Chiba-Falek O, Kerem E, Shoshani T, Aviram M, Augarten A, Bentur L, Tal A, Tullis E, Rahat A, Kerem B: The molecular basis of disease variability among cystic fibrosis patients carrying the 3849+ I 0kb C-T mutation. Genomics 1998, 53:276-283
1I. Dumur V, Gervais R, Rigot J-M, Delomel-Vinner E, Decaestecker B, Lafitte J-J, Roussel P: Congenital bilateral absence of the vas deferens (CBAVD) and cystic fibrosis transmembrane conductance regulator (CFTR): correlation between genotype and phenotype. Hum Genet 1996, 97:7-10

12. Cuppens $H$, Lin $W$, Jaspers $M$, Costes $B$, Teng $H$, Vankeerberghen $A$, Jorissen M, Droogmans G, Reynart I, Goossens M, Nilius B, Cassiman J-J: Polyvariant mutant cystic fibrosis transmembrane conductance regulator genes. The polymorphic (TG)m locus explains the partial penetrance of the T5 polymorphism as a disease mutation. J Clin Invest 1998, 10 I:487-496

13. Friedman KJ, Heim RA, Knowles MR, Silverman LM: Rapid characterization of the variable length polythymidine tract in the cystic fibrosis (CFTR) gene: association of the 5 T allele with selected CFTR mutations and ist incidence in atypical sinopulmonary disease. Hum Mut 1997, 10(2): 108-I I5

14. Kerem B, Rommens JM, Buchanan JA, Markiewicz D, Cox TK, Chakravarti A, Buchwald M, Tsui LC: Identification of the cystic fibrosis gene: genetic analysis. Science 1989, 245: 1073-80

15. Riordan JR, Rommens JM, Kerem B, Alon N, Rozmahel R, Grzelczak Z, Zielenski J, Lok S, Plavsik N, Chou JL, Drumm ML, lanuzzi MC, Collins FS, Tsui LC: Identification of the cystic fibrosis gene: cloning and characterization of complementary DNA. Science 1989, 245: 1066-73(Erratum, Science 1989,245: 1437).

16. Rommens JM, lannuzzi MC, Kerem B, Drumm ML, Melmer G, Dean M, Rozmahel R, Cole JL, Kennedy D, Hidaka N, Zsiga M, Buchwald M, Riordan JR, Tsui LC, Collins FS: Identification of the cystic fibrosis gene: chromosome walking and jumping. Science 1989 , 245: $1059-65$

17. Wilschanski M, Zielenski J, Markiewicz D, Tsui LC, Corey M, Levison $\mathrm{H}$, Durie PR: Correlation of sweat chloride concentration with classes of the cystic fibrosis transmembrane conductance regulator gene mutations. J Pediatr 1995, I 27:705-7I0

18. Chu CS, Trapnell BC, Curristin S, Cutting GR, Crystal RG: Genetic basis of variable exon 9 skipping in cystic fibrosis transmembrane conductance regulator mRNA. Nature Genet 1993, 3:151156

19. Dequeker E, Cuppens H, Dodge J, Estivill X, Goossens M, Pignatti PF, Scheffer H, Schwartz M, Schwarz M, Tummler B, Cassiman J-J: Recommendations for quality improvement in genetic testing for cystic fibrosis. European concerted action on cystic fibrosis. Eur Hum Genet 2000, 8(Suppl 2):S2-24

20. Audrezet MP, Mercier B, Guillermit H, Quere I, Verlingue C, Rault G, Ferec C: Identification of $\mathbf{1 2}$ novel mutations in the CFTR gene. Hum Mol Gen 1993, 2:51-54

21. Greil I, Wagner K, Eber E, Zach M, Rosenkranz W: Molecular and clinical findings in Austrian cystic fibrosis patients with mutations in exon I I of the CFTR gene. Wien Klin Wochenschr 1995, 107(15):464-469

22. Personal communication with our referring clinicians (General Hospital Wien (AKH), Hospital Lainz, Preyer'sches Hospital, Sozialmedizinisches Zentrum-Ost, Wilhelminen Hospital, Vienna, Austria).

23. Wang X, Myers A, Saiki RK, Cutting GR: Development and evaluation of a PCR-based, line probe assay for the detection of 58 alleles in the cystic fibrosis transmembrane conductance regulator (CFTR) gene. Clin Chem 2002, 48(7): I I 2 I- I I 23

\section{Pre-publication history}

The pre-publication history for this paper can be accessed here:

http://www.biomedcentral.com/1472-6890/2/4/prepub 